\title{
A categoria de experiência na teoria feminista
}

\section{Las voces de la experiencia: el viraje de la filosofía feminista.}

BACH, Ana María.

\author{
Buenos Aires: Biblos, 2010. 174 p.
}

O conceito de experiência tem sido um tema polêmico nos estudos filosóficos desde a Antiguidade e problemático dentro de uma concepção positivista de ciência. Na contemporaneidade, o papel das experiências começa a ser valorizado tanto pelas Ciências Sociais como pela filosofia feminista nos processos de compreensão da produção do conhecimento e da ação social, cujos estudos se contrapõem à ideia de objetividade pura e de sujeito universal. No entanto, é o feminismo como movimento social e intelectual que mais valorizou a centralidade das "experiências das mulheres". Nesse sentido, o feminismo como teoria permitiu distinguir conhe-cimentos situados por meio de uma proposta epistemológica alternativa que trouxe para o cenário acadêmico novos sentidos sobre o que se considera conhecimento e um processo de ressignificação da objetividade e de outras categorias centrais nas ciências humanas e sociais, como é o caso da categoria de experiência (p. 9).

O estudo de Ana María Bach coloca em cena o conceito de experiência, que é ao mesmo tempo tão reivindicado quanto questionado dentro do debate acadêmico, sobretudo, em contextos dos estudos culturais. Nos estudos feministas, em geral, a noção de experiência tem sido utilizada para fins de produção do conhecimento e para a compreensão de processos de subjetivação, porém, na visão da autora, ela é, ainda, pouco problematizada teoricamente. As mulheres passaram a valorizar o modo de pensar contextual e narrativo em lugar do formal e abstrato, preferido pelos homens, e, com isso, mostraram como a posição de sujeito e as experiências distintas interferem significativamente na produção do conhecimento. Na década de 1970 até o final do século passado houve uma explosão da teorização acadêmica e política dentro do campo feminista, com a consequente institucionalização dos estudos feministas nos anos 1980, que se solidificaram por meio da criação de programas e departamentos dedicados aos "Estudos das Mulheres" (p. 10). Levando em conta essa situação e a centralidade da categoria "experiência das mulheres", reivindicada nos estudos feministas, a autora se propõe a reconstruir a valorização da experiência como categoria epistemológica, por meio de um minucioso trabalho de sistematização teórica, a partir da produção das principais feministas norteamericanas, no período de 1980-2000.

Desse modo, o livro Las voces de la experiencia é resultado de uma investigação teórica que integra parte da tese de doutorado 
em Ciências Sociais de Ana María Bach, pela Universidade de Buenos Aires, na qual a autora se dedica à análise das contribuições feministas para pensar a experiência como categoria teórica. Utiliza-se de uma produção acadêmica proveniente, sobretudo, da área da Filosofia e das Ciências Sociais e, praticamente, toda em língua inglesa. Ela analisa produções acadêmicas de diferentes autoras que se utilizam de perspectivas da filosofia analítica, do pós-estruturalismo, da fenomenologia, da teoria crítica e do pragmatismo, entre outras. Nesse processo de análise, procura sempre conectar a produção e suas distinções teóricas com a situação de cada autora, isto é, com a sua condição de classe, de orientação sexual, de raça e com o seu processo de formação acadêmica e de trânsito migratório, evidenciando concretamente como o conhecimento se vincula com a biografia e a experiência pessoal de vida, que é sempre sexuada, encarnada e situada. Bach estrutura o livro em quatro capítulos e um apêndice final, no qual retoma uma série de temas complementares à discussão que realiza ao longo de sua obra.

No primeiro capítulo a autora aborda a relação entre experiência e subjetividade. Primeiramente, apresenta um recorrido histórico acerca da noção de experiência, as contribuições que vêm da fenomenologia e do pragmatismo e a sua ressignificação por parte da teoria feminista. Nesse sentido, a experiência sexualizada e situada passa a ser valorizada nos processos de formação da subjetividade e na produção do conhecimento, recordando que essa experiência é constituída de três dimensões - psicológica, política e cognitiva - que estão intrinsecamente unidas. Em seguida, Bach apresenta a relação entre a construção mútua da subjetividade e da experiência, na qual a autoconsciência feminista exerce um pape fundamental. Em função disso, constrói uma espécie de genealogia da história do movimento feminista sobre as práticas dos grupos de autoconsciência, analisando-os a partir da perspectiva fenomenológica de Sandra Barly. Por fim, a autora destaca a contribuição original de Teresa de Lauretis, justamente por essa introduzir - papel da semiótica e articular experiência, sexualidade e diferença nos processos de subjetivação. A definição de experiência construída por De Lauretis, que leva em conta a interação semiótica do sujeito com a realidade social (p. 37), tem sido de grande importância para os estudos feministas, que consideram a centralidade da experiência das mulheres nos processos de produção do conhecimento.
No segundo capítulo Ana María Bach discute a relação experiência e política. Para isso, destaca as vozes das experiências de mulheres latinas/hispanas, negras, lesbianas e trabalhadoras, as quais, por meio da relação margens e centro, criticam a parcialidade do pensamento teórico das feministas da White, Anglo-Saxon and Protestant (WASP). Isso por ser um pensamento pautado em uma experiência única e universal, cujos pressupostos teóricos e analíticos se tornavam insuficientes para da conta da variedade das experiências humanas. Nessa perspectiva de crítica, a autora analisa a contribuição que vem do pensamento de bell hooks, Gloria Evangelina Anzaldúa, Maria Cristina Lugones e Chandra Talpade Mohanty, cujas feministas produziram suas teorias a partir da experiência de estar nas margens. Elas fazem notar a existência de uma tríplice opressão entre raça, classe e sexo, ou a que se produz por meio de fronteiras específicas. Com suas especificidades, propõem alternativas que vão desde as margens, passando pela produção de uma linguagem própria até a construção política de um feminismo sem fronteiras.

O terceiro capítulo é dedicado à reflexão sobre a dimensão epistemológica da experiência. Para isso, Ana Bach parte de uma posição crítica em relação à epistemologia tradicional, evidenciando que a característica que distingue a epistemologia feminista é o fato de essa valorizar a experiência feminina do cotidiano, no processo da produção do conhecimento científico. Baseada na distinção feita por Sandra Harding, a autora comenta as três abordagens da epistemologia feminista, as pesquisadoras que integram cada uma das correntes e suas distintas posturas teóricas no que se refere à importância da dimensão cognitiva da experiência. Com isso, Bach ressalta que a grande contribuição das epistemologias feministas tem sido o fato de essas mostrarem que a siłuação, a posição e a circunstância em que se encontra determinado sujeito do conhecimento refletem fortemente em sua produção acadêmica.

No último capítulo, Bach analisa a relação entre experiência e linguagem a partir das propostas do pós-estruturalismo e da fenomenologia, cujo tema segue sendo polêmico. Comenta o impacto do ensaio "A experiência como prova", da historiadora norte-americana Joan W. Scott, que trata da experiência como um evento linguístico, cujo arcabouço teórico se mostra insuficiente para dar conta das experiências que não são articuladas em discursos, como as de grupos subalternos, inclusive 
mulheres. Em seguida, retoma as contribuições de Iris Marion Young e Linda Martin Alcoff, que, inspiradas em Maurice Merleau-Ponty, indicam outras possibilidades para pensar e teorizar a experiência diante da redução das formações discursivo-linguísticas. A importância deste capítulo está nos argumentos que a autora desenvolve para mostrar como a teoria feminista pode oferecer explicações mais integrais adotando ferramentas metodológicas da fenomenologia que, antes de se oporem, complementam as explicações pós-estruturalistas.

O livro apresenta, ainda, quatro apêndices, como uma espécie de ensaio acadêmico, nos quais a autora expõe sua opinião sobre diversos temas que perpassam a sua obra. No primeiro "Do ativismo à universidade: os feminismos no contexto estadunidense" -, menciona o processo de institucionalização do feminismo nos Estados Unidos, seus desafios, desdobramentos e impactos em diferentes áreas acadêmicas. No segundo - "Razões e não razões dos 'pós'” -, a autora se acerca da conflitante aliança entre feminismo e pós-modernismo e as concepções de algumas feministas sobre essa relação. Distingue e esclarece termos como pósestruturalismo e pós-modernismo que, usualmente, são confundidos. No terceiro apêndice "Isso que chamamos patriarcado" -, aborda sobre a dinamicidade da estrutura patriarcal e a compreensão da noção de patriarcado presente nos distintos desdobramentos teóricos do feminismo, e, levando em conta as críticas feitas ao patriarcado, tenta uma nova definição, em cujo núcleo característico está a opressão das mulheres; opressão essa que assume roupagens específicas em cada cultura. E, por fim, em "Biobibliografias; vidas e teorias", a autora descreve a relação entre a biografia e a produção teórica das autoras que foram abordadas, completando dados e comentários que aparecem no decurso dos capítulos do livro. Enfim, pode-se afirmar que o estudo de Ana María Bach, centrado na categoria de experiência, se apresenta como uma obra importante dentro dos estudos feministas por diferentes fatores, tais como por seu caráter transdisciplinar; por colocar em evidência a necessidade de problematizar e teorizar a experiência como uma categoria epistemológica para a produção do conhecimento, seguindo a mesma insistência de De Lauretis' ${ }^{2} e$ Alcoff; ${ }^{2}$ por oferecer uma síntese das diferentes autoras norte-americanas que em suas teorias estabeleceram certa relação entre experiência, subjetividade, conhecimento, política e linguagem; por mostrar concretamente que a experiência e a consciência da opressão, desde uma posição de classe, raça, etnia e da postura consciente de estar nas margens, têm sido frutíferas para o pensamento feminista, permitindo que esse fosse incorporando novas abordagens teóricas e alternativas de libertação, seja por meio dos processos de construção de saberes, seja pela ação política.

\section{Notas}

'Teresa de LAURETIS, 1984.

2 Linda M. ALCOFF, 1999.

\section{Referências}

ALCOFF, Linda M. "Merleau-Ponty y la teoría feminista sobre la experiencia". MORA Revista del Instituto Interdisciplinario de Estudios de Género, Buenos Aires, Facultad de Filosofía y Letras, n. 5, p. 122-138, 1999.

DE LAURETIS, Teresa. "Semiótica y experiencia". In:_. Alicia ya no: feminismo, semiótica, cine. Madrid: Ediciones Cátedra, 1984. p. 251 294.

Neiva Furlin Universidade Federal do Paraná 